\title{
Reading Habits of the Students with Bengali Medium Background at the English Medium Private Universities in Bangladesh
}

\author{
Md. Golam Hoshain Mirza \\ Assistant Professor \\ Department of English, Northern University Bangladesh, Bangladesh \\ Tel: 880-181-738-5220Ｅmail: raktimmirza@yahoo.com \\ Khaled Mahmud (Corresponding Author) \\ Lecturer \\ Institution of Business Administration, University of Dhaka \\ Dhaka-1000, Bangladesh \\ Tel: 880-171-253-6013Ｅmail: khaled@iba-du.edu
}

Received: March 22, 2012

Accepted: March 28, 2012 Online Published: May 3, 2012

doi:10.5539/hes.v2n2p100

URL: http://dx.doi.org/10.5539/hes.v2n2p100

\begin{abstract}
This paper investigates into the reading habits of the English medium private university students with Bengali medium background. It analyses the realities in the context, which are both nurturing the old and shaping new reading habits of the students. The data gathered by means of interview schedule have been analyzed both quantitatively and qualitatively. The data shows that our students' reading habits - avoiding text books, memorizing readymade things for exam purposes, very little reading in not only English but Bengali as well - do not change remarkably during their tertiary level of study at the private universities. Rather they are further solidified and nurtured by the teachers' supply of lecture notes, an acute lack of motivation for reading the study materials in English, and the negative backwash of the exam system. These causes of the undesirable reading habits can be removed only if all the teachers dealing with the students come forward and work together with the English teachers for a long period of time to achieve the aims.
\end{abstract}

Keywords: Reading habits, English, Bengali, Bangladesh, Private university

\section{Introduction}

The context of private universities in Bangladesh is different from that of the public ones in a number of ways. Some of the more relevant points of difference are:

a) The medium of instruction at all the private universities is solely English.

b) Most of their students are from Bengali medium schools and colleges and consequently not very good at English.

c) Lecturing on a particular course, setting of the questions, and evaluation of the scripts are all in the hand of one particular teacher.

d) They are well equipped with modern facilities like OHPs, computers with Internet connection, multimedia, etc.

With these special features, the private universities are expected to bring about a big positive change in the reading habits of the students. But the expectation is not being fulfilled for four reasons. Firstly, the English foundation courses are few in number. Secondly, the students are not motivated to read their books. Thirdly, the teachers do not mind language deficiency. And finally, they find it easy to pass the exams. The context can be free from these barriers only if the English teachers' work is shared by all the other course teachers, and if forming good reading habits is taken up as a long term goal by everybody concerned: students, teachers, and the university administration.

\subsection{Literature Review}

Students with Bengali medium background in our country are mostly very weak at reading English. These students have some characteristics in common. These are predictors or symptoms as well as causes of their being weak at reading in English. Quader (1999) has found out many of them. Three of them are: 
a) The weak readers' input through reading is irregular in nature and insufficient in amount.

b) The weak readers do not comprehend what they read in English. In consequence, reading appears very hard and boring to them.

c) They find reading difficult also because they do not have the essential schematic knowledge.

Besides, reading becomes more difficult for them if the context contains vocabulary with a different meaning from what they already know.

Thus, Quader has found out how to identify poor readers of English but she has not pointed out why the students have these problems or how they can be solved.

Among the researchers who have found out the reasons, Jared (2008) states that family background plays an important role in determining the reading habits of the learners. Readers usually get stimulation and encouragement to read both in L1 (their first language) and L2 (the second language) from their families. A student coming from a family with no tradition of reading can hardly be expected to form good reading habits.

Secondly, a part of the reason is the schools and colleges where the students go. The teachers in Bangladesh teach English following methods which do not encourage good reading habits (Rabbani, 1999; Ahmed, 1999; Hoque, 1999).

Thirdly, the economic condition of the family has some influences on the formation of reading habits in the target language (Sabih, 1999). Learners from a poverty stricken family have very few accesses to the target language. They cannot go to better institutions with better opportunities.

Fourthly, reading habits are framed by the learners' motivation and interests (Nunan, 1988). But the students going to Bengali medium schools and colleges in our country are not very interested or instrumentally motivated to read their things in English. It is because the exam system is nurturing a tendency of avoiding reading in English (Rahman, 1999). The students mostly read for exam purposes. It is because of the negative backwash of the testing system. Ahmed (1999) has found out that most of the learners prefer to read notes rather than textbooks. They are encouraged to do so by the fact that the questions set for the exams are very repetitive (Akter, 1999).

Against this bleak background of reading in English, the private universities are expected to bring about a positive change at the tertiary level. But as a teacher with seven years' experience of the context, the researcher has seen that the target is hardly being achieved. Therefore, he investigated into the situation to find out the reasons and what reforms can be carried out.

\section{Methodology}

The study was conducted during March - 2011 on 100 samples studying at private universities in Bangladesh. All the samples were from Bengali medium schools and colleges. The researcher selected the samples only from the senior students studying in the last four semesters of their respective four-year honours programs so as to get information from students with at least 32 months' experience of studying at the university. As the present study does not have the scope of including all the private universities, the samples were chosen from ten of them - 10 samples from each university. The universities are American International University - Bangladesh (AIUB), ASA University Bangladesh, Bangladesh University, Dhaka International University, International Islamic University Chittagong (IIUC), Northern University Bangladesh (NUB), Southeast University, The University of Asia Pacific (UAP), University of Development Alternative (UODA) and World University of Bangladesh (WUB). The researcher believes that ten private universities make up about $20 \%$ of the sector and, therefore, the finding(s) of the study is representative of the whole scenario.

To collect data, the researcher prepared and used an interview-schedule. Before the samples answered the questions, the researcher explained them to the samples individually. It was to ensure that the information given by the samples was well thought out. The researcher adopted both the quantitative and the qualitative approaches for the study because some information was quantitative in nature and required quantitative interpretation while some questions were open ended and the information elicited by them needed qualitative treatment.

\section{Data Analysis}

The questions in the questionnaire were set to elicit data about three different issues related to the students' reading habits:

a) The students' familial background of reading in L1 and L2

b) The things that they read and their motivations

c) The problems which they are facing and their way of dealing with them 
And as the number of the samples is 100 , the number of responses is the same as their percentages.

\subsection{Their Familial Background of Reading}

Students' reading habits are formed by their respective family tradition (Jared, 2008). How much importance a family gives to reading can be measured by the number of books it possesses. Question 1 (How many and what types of books in Bengali and English does your family have?) was set to gather information about how much importance the students' families give to reading in both L1 and L2.

Chart 1 shows that a family on average has more textbooks in English (24.55) than in Bengali (23.80). On the other hand, whereas the average number of other types of books in Bengali owned by a family is 58.34, that of the books of this sort in English is only 13.51. And we get a worse picture if we separate 20 of the families from the rest.

As Chart 2 presents, 20\% students are from families which have as many as 216.4 other types of books in Bengali and 50.3 in English. But 80\% of the students are families that do not have more than 18.83 other types of books in Bengali and 4.31 in English. However, in every case the number of books in English (not textbooks) is the least in number. This is clearly because reading in English at home is hardly given any importance.

\subsection{Things They Read and Their Motivation:}

Four questions were asked to find out how often the students read their text books in English, what else they read in L1 and L2, and what motivations they have.

In response to Question 2 (Do you read your textbooks in English?), the respondents have reported that although 77\% of them read their textbooks some time or other, $23 \%$ of them do not read them at all. This great number of students does not read their text books because their English is not good enough and because they can pass the exams without reading them.

Apart from their text books, for different purposes, the students read some other types of things both in L1 and L2. The list of reading materials in the first column of the following table was given to the respondents to be ticked.

As we see in Table 1, the students read some things more in English and some other in Bengali more. They read class notes, notebooks, class handouts and reference books more in English. As for newspapers, magazines and storybooks, they read them more in Bengali. Besides, 23\% students read things on the net. Some of the respondents have stated why they read certain things in English more than the others. They read in English mainly for exam purposes. On the other hand, they read things in Bengali because they enjoy reading them. And when Question 4 (What things in Bengali have you read in the last seven days?) was asked, it was found out that newspapers (33\%) are the most preferred reading materials in Bengali. Next to newspapers are novels (16\%), storybooks (13\%), magazines (9\%), poems (5\%), history books (4\%), and the textbooks of their private students (2\%). Besides, $1 \%$ students in each case read eight other types of things. The students read these things mostly for pleasure. But the important thing is that few students read things in Bengali regularly.

Memorization is a common reading habit of all weak readers. Question 5 (Do you memorize things for exam purposes? If yes, what do you memorize?) was used to find out information in this regard.

As we see in Chart 3, while $47 \%$ students do not memorize things for exam purposes, $53 \%$ of them do. Some of the respondents have also mentioned the things which they memorize for exam purposes. Among these are class notes, handouts, quotations, readymade answers to the questions, the headlines or topic sentences of the notes, and difficult words and terms. Whatever be the things that they memorize, they memorize them because they cannot produce any meaningful English and they are pretty sure about the questions that they will have to answer in the exam hall.

\subsection{Their Problems and Way of Dealing with Them}

In the final phase of the questionnaire, as has been mentioned earlier, the aims of the questions were to find out what problems the weak students are facing and how they are dealing with them. Likewise, in answer to Question 6 (What problems are you facing for being weak at reading in English?), the students have mentioned different problems and in most cases one particular student has reported more than one problem.

As Table 2 shows, the poor readers are facing four types of problems related to their academic activities:

- $80 \%$ of the interviews cannot write their exam papers properly.

- $25 \%$ have opined that it takes them a lot of time to memorize their things in English.

- $10 \%$ have reported that they cannot take part in many of the extracurricular activities, for example debating, with success.

- $65 \%$ think that, in spite of working hard, they get poor grades in the exams. 
- $\quad$ On the other hand, their problems which are mental in nature are:

- $\quad 75 \%$ of the interviewees suffer from fears and anxieties. They are afraid of the lessons and the exams. They are anxious about their class activities and grades.

- $60 \%$ of the students find their lessons very boring.

- $45 \%$ of the interviewees suffer from diffidence.

Thus, the problems which the students at the private universities are suffering from for their being weak at reading are many in number and far-reaching in nature.

As the weak students do not feel comfortable with their study at an English medium university, some of them drop out. But most of them continue. Question 7 (How is it possible to pass the exams with very little English?) was used to find out how the weak students manage to do so by passing the exams.

Table 3 shows that there are a few things which help the poor readers pass their exams and ultimately get their degrees. Firstly, the students have the necessary notes, handouts and guidebooks. Secondly, the teachers do not care much for language accuracy. Thirdly, the students get the marks for attendance by simply remaining present in the class. Fourthly, they can copy things like assignments and reports prepared by other better students. Finally, they read translations, develop some ideas about the courses, and thus manage to pass the exams.

\section{Discussion}

The reading habits of students are formed by their family traditions and the economic condition of their parents (Jared, 2008; Sabih, 1999). In this respect, our students do not often belong to families with hundreds of books. 80\% of the students are from families which value reading in English so much as to own only 4.31 books (not textbooks) in English (See Chart 1 \& 2). It should be kept in mind that these families are all comfortably well-off. So, the poverty of books in English at home, at least in $80 \%$ cases, is because of their giving little importance to reading in English.

The more we read, the better readers we grow (Quader, 1999). In this respect, the private university students coming from Bengali medium schools and colleges are reading little in English and consequently hardly growing any better readers. The students do not read their textbooks regularly. As many as 23\% students (See the discussion for Question 2) do not read their textbooks at all. These students either depend on their friends or read Bengali translations of their textbooks in English if they are available on the market. However, beside textbooks, some students read some other types of things in English.

The students generally prefer to read things in Bengali. And their reading habits in Bengali (L1) can help them read things in English better (Comeau, Cormier, Grandmaison, \& Lacroix, 1999; Deacon, Wade-Woolley, \& Kirby, 2007; MacCoubrey, Wade-Woolley, Klinger, \& Kirby, 2004; Alderson, 2000; Jared, 2008). But the input in Bengali is not remarkable either (See the discussion for Question 3 \& 4). Thus, it seems that the real reason for not reading a lot is not caused by their being unable to read only, it is also because of their not willing to do so.

The students in Bangladesh mostly read to get marks or grades (Ahmed, 1999). To obtain them, the weak students usually depend on memorization of readymade things. And this habit has not changed at all. Contrarily, it is being nurtured at the English medium universities again by the availability of handouts, notes, translations, etc. About $54 \%$ of the students memorize things for their exams (See Chart 3). The fact that the students have readymade things which they can memorize and thus pass their exams is the most damaging reality. Of course, the data tell negatively of the exams; the questions are either repetitive or predictable. This is an important reason why the students are not developing good reading habits. In addition, the teachers' generosity in giving undeserved or inflated marks is also a big demoralizing factor (See the discussion for Question 7).

However, the positive side of the whole affair is that the students, although they are somehow passing from one semester to another and ultimately from the university into the market, they are aware of the problems which they are suffering from for not having good reading habits. And this awareness is the great motivation on which the foundation can be laid for bringing about a good change in the scenario. The weak students are undergoing great academic and mental troubles. They are unable to obtain good grades despite hard work. They are diffident as they cannot take part in any prestigious extracurricular activities. They are afraid and anxious about their future (See the discussion for Question 6). These suffering students can be persuaded to give the tremendous labour which is necessary to develop their level of proficiency in English and ultimately replace their bad reading habits with good ones. 


\section{Conclusion and Recommendations}

There have been few changes in the students' reading habits. The students are surfing the net frequently. As an alternative to their textbooks in English, they are reading the translations. On the other hand, many of the reading habits have remained unchanged. The most important one is the habit of memorization. The students are memorizing readymade things for the exams.

The immersion, i.e. making the students develop desirable reading habits so that they can cope up with their studies at the English medium universities, is not very successful for a number of reasons. Firstly, the students are mainly from families which care little for reading. Secondly, the students read for marks and grades. As a result, they do not read things if they are not useful for the exams. Finally, and most importantly, the exams are not without their negative backwash. The students memorize readymade things because the questions set for the exams are repetitive and that is why predictable. On top of that, the teachers seem to be too kind in both giving class notes to the students and overlooking language deficiency while checking their scripts.

Thus the researcher's belief that the reading habits of the students with Bengali medium background at the English medium private universities do not undergo any positive change is partially correct. Changes in the reading habits of the students seem to be taking place though they are not very remarkable. For better results in this regard, the following steps can be taken:

a) The questions set for the exams should be creative, not repetitive.

b) The immersion or replacement of the traditional reading habits by the good ones should be treated as a long term job: it cannot be done in 8/12 months by the traditional 2/3 English foundation courses.

c) The task of developing English reading skills and good reading habits cannot be done by the English teachers alone. All other course teachers should share the work.

d) The weak students should be divided into small groups and put under the supervision of the teachers for the whole period of their study at the university. A particular teacher will ensure a regular input through reading for the students of a particular group.

e) All teachers should make it clear to the students that a gradual development of English reading skills is a must. They can do it by giving more and more importance to language accuracy.

f) The teachers should avoid giving the same homework to every student and penalize all sorts of copying severely.

However, before conclusion, it must be acknowledged that for more accurate picture of the situation we need more studies. It is not only because the information provided by the samples might be slightly faulty but also because the samples are an insignificant part of the whole.

\section{References}

Ahmed, S. (1999). 'The Problem of Teaching English Grammar to Bengali-Speaking Students'. Proceedings of the International Conference, Jan 31 - Feb 2, 1999: National and Regional Issues in English Language Teaching: International Perspectives. Dhaka: The British Council, 1999.

Akter, M. Z. (1999). 'English Language Testing System in Bangladesh and Communicative Competence: An Investigation'. Proceedings of the International Conference, Jan 31 - Feb 2, 1999: National and Regional Issues in English Language Teaching: International Perspectives. Dhaka: The British Council, 1999.

Comeau, L., Cormier, P., Grandmaison, E., \& Lacroix, D. (1999). 'A longitudinal study of phonological processing in children learning to read in a second language. Journal of Educational Psychology, 91, 29-43. http://dx.doi.org/10.1037/0022-0663.91.1.29

Deacon, S. H., Wade-Woolley L., \& Kirby, J. (2007). Crossover: The role of morphological awareness in French $\begin{array}{lllll}\text { immersion children's } \quad \text { reading. Developmental } & \text { Psychology, } & \text { 43, }\end{array}$ http://dx.doi.org/10.1037/0012-1649.43.3.732

Hoque, S. (1999). 'ELT Issues in Bangladesh: An Overview'. Proceedings of the International Conference, Jan 31 - Feb 2, 1999: National and Regional Issues in English Language Teaching: International Perspectives. Dhaka: The British Council, 1999.

Jared, D. (2008). 'Assessment of reading ability in French immersion students'. Encyclopedia of Language and Literacy Development (pp. 1-7). London, ON: Canadian Language and Literacy Research Network. [Online] Available: http://www.literacyencyclopedia.ca/pdfs/topic.php?topId=239 (December 19, 2011) 
MacCoubrey, S. J., Wade-Woolley, L., Klinger, D., \& Kirby, J. (2004). Early identification of at-risk L2 readers. The Canadian Modern Language Review, 61, 11-28. http://dx.doi.org/10.3138/cmlr.61.1.11

Nunan, D. (1988). The Learner-centred Curriculum. Cambridge: Cambridge University Press.

Quader, D. A. (1999). 'Students' perception of difficulty in English Course'. Proceedings of the International Conference, Jan 31 - Feb 2, 1999: National and Regional Issues in English Language Teaching: International Perspectives. Dhaka: The British Council, 1999.

Rabbani, F. (1999). 'Different Attitudes among ESL Learners in Bangladesh'. Proceedings of the International Conference, Jan 31 - Feb 2, 1999: National and Regional Issues in English Language Teaching: International Perspectives. Dhaka: The British Council, 1999.

Rahman, A. M. M. H. (1999). 'English Language Teaching in Bangladesh: didactics on the pragmatics of a language teaching policy’. Proceedings of the International Conference, Jan 31 - Feb 2, 1999: National and Regional Issues in English Language Teaching: International Perspectives. Dhaka: The British Council, 1999.

Sabih, H. (1999). 'How I started learning English: A Situation Analysis through A Personal Account'. Proceedings of the International Conference, Jan 31 - Feb 2, 1999: National and Regional Issues in English Language Teaching: International Perspectives. Dhaka: The British Council, 1999.

Table 1. Preferred Reading Materials beside Textbooks

\begin{tabular}{|l|l|l|}
\hline $\begin{array}{l}\text { Question 3: Tick the things you read. Please write if you read } \\
\text { anything else, and why we read them. }\end{array}$ & In Bengali & In English \\
\hline Class notes & 12 & 87 \\
\hline Notebooks & 17 & 74 \\
\hline Class handouts & 12 & 85 \\
\hline Newspapers & 73 & 54 \\
\hline Magazines & 58 & 53 \\
\hline Story books & 59 & 44 \\
\hline Reference books & 8 & 82 \\
\hline The Net & 23 & 00 \\
\hline
\end{tabular}

Source: Field work, March - 2011

Table 2. Students' Problems Caused by their Poor Reading Skills

\begin{tabular}{|l|l|l|}
\hline Types of problems & Problems & Number of Response \\
\hline \multirow{4}{*}{ Academic } & Cannot write the exam papers properly & 80 \\
\cline { 2 - 3 } & Need a lot of time to memorize & 25 \\
\cline { 2 - 3 } & Cannot take part in many extracurricular activities & 10 \\
\cline { 2 - 3 } & Do not get very good grades & 65 \\
\hline \multirow{3}{*}{ Mental } & Feeling afraid and anxious & 75 \\
\cline { 2 - 3 } & Feeling very bored & 60 \\
\cline { 2 - 3 } & Don't feel confident & 45 \\
\hline
\end{tabular}

Source: Field work, March - 2011

Table 3. Students' Ways of Passing the Exams

\begin{tabular}{|l|l|}
\hline Ways of passing the exams & Number of Response \\
\hline Memorizing notes / handouts / guidebooks & 80 \\
\hline Teachers caring little for language accuracy & 40 \\
\hline Getting the full marks for attendance & 10 \\
\hline Copying assignments and other things & 5 \\
\hline Reading translations & 5 \\
\hline
\end{tabular}

Source: Field work, March - 2011 


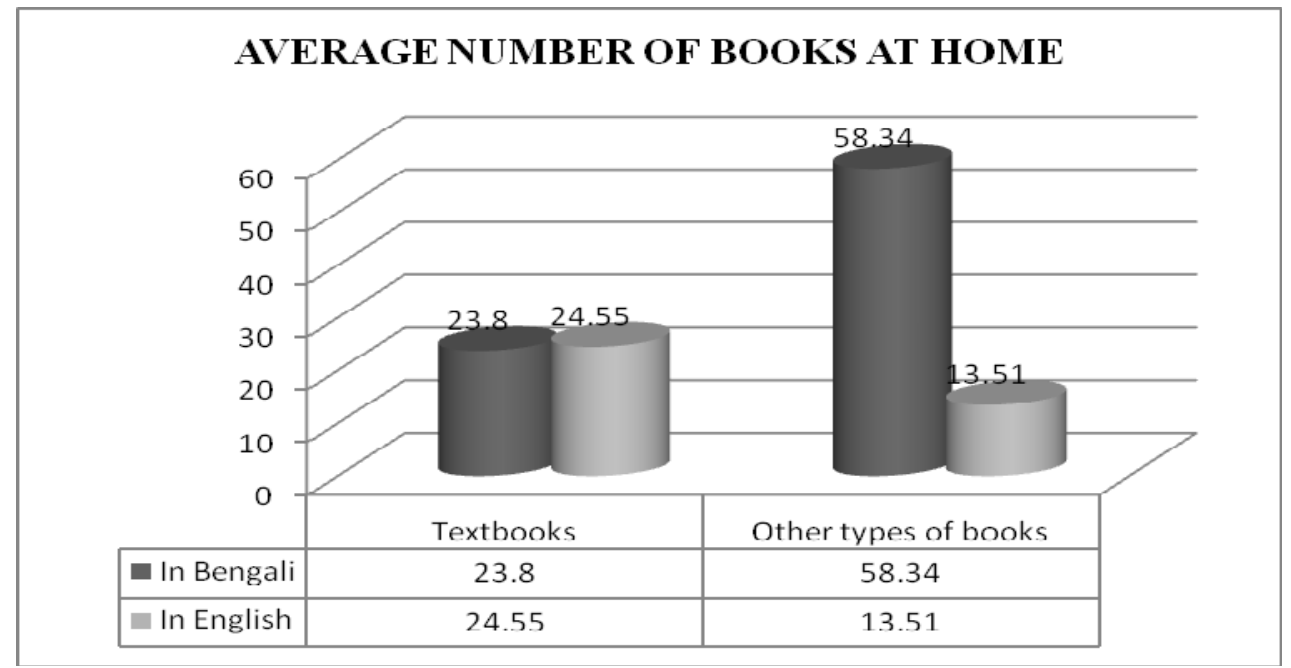

Chart1. Source: Field work, March - 2011

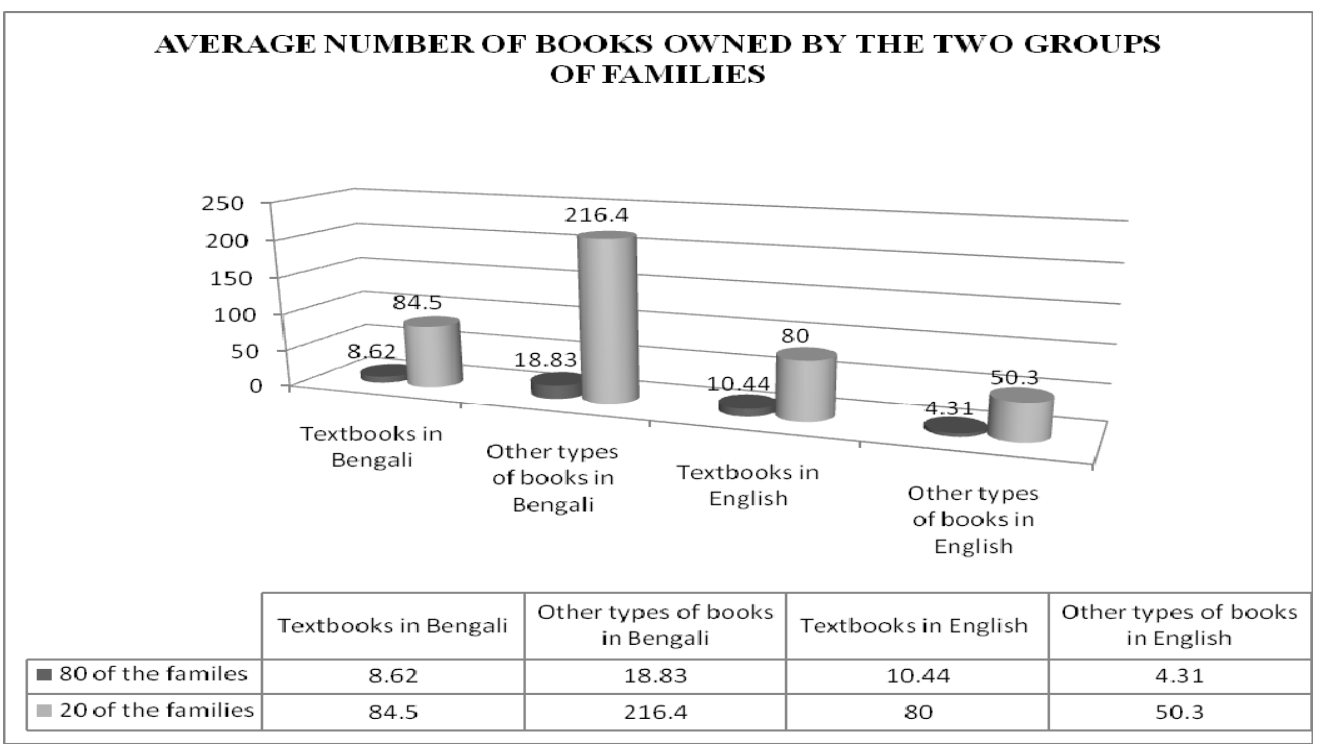

Chart 2. Source: Field work, March - 2011

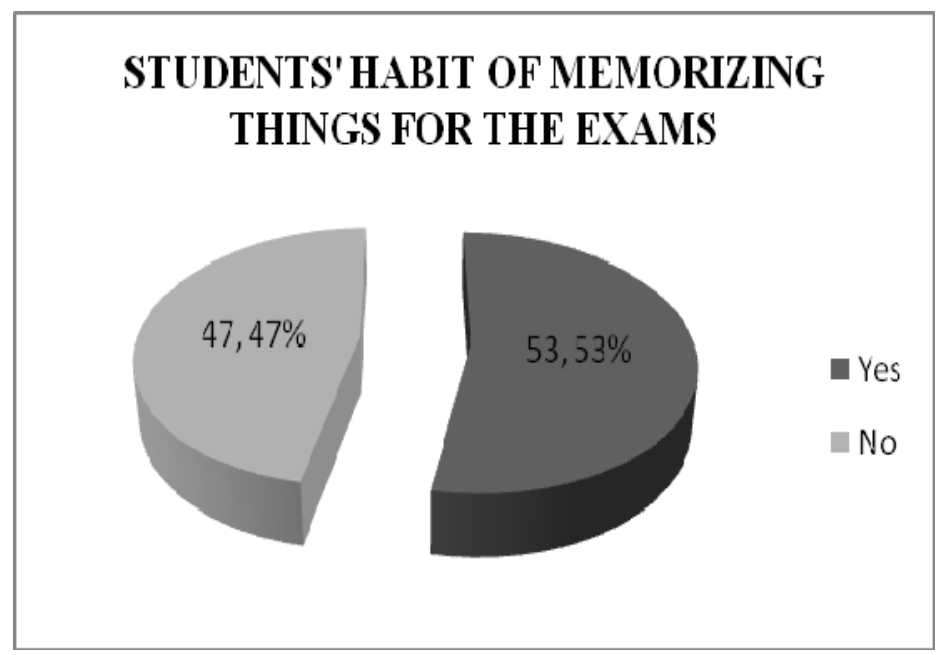

Chart 3. Source: Field work, March - 2011 